\title{
Determination of the Diagnostic Values of Asymmetric Dimethylarginine as an Indicator for Evaluation of the Endothelial Dysfunction in Patients with Rheumatoid Arthritis
}

\author{
Dejan Spasovski, ${ }^{1}$ Arif Latifi, ${ }^{2}$ Bashkim Osmani, ${ }^{1}$ \\ Svetlana Krstevska-Balkanov, ${ }^{2}$ Irena Kafedizska, ${ }^{1}$ Maja Slaninka-Micevska, ${ }^{3}$ \\ Beti Dejanova, ${ }^{4}$ Sonja Alabakovska, ${ }^{5}$ and Trajan Balkanov ${ }^{3}$ \\ ${ }^{1}$ Department of Rheumatology, University Clinical Centre, Skopje, Macedonia \\ ${ }^{2}$ Department of Hematology, University Clinical Centre, Skopje, Macedonia \\ ${ }^{3}$ Department of Preclinic Pharmacology, University Clinical Centre, Skopje, Macedonia \\ ${ }^{4}$ Department of Physiology, University Clinical Centre, Skopje, Macedonia \\ ${ }^{5}$ Institute of Preclinic Biochemistry, University Clinical Centre, Skopje, Macedonia \\ Correspondence should be addressed to Dejan Spasovski; drspasovski@yahoo.co.uk
}

Received 4 March 2013; Revised 19 April 2013; Accepted 19 April 2013

Academic Editor: Pierre Youinou

Copyright (c) 2013 Dejan Spasovski et al. This is an open access article distributed under the Creative Commons Attribution License, which permits unrestricted use, distribution, and reproduction in any medium, provided the original work is properly cited.

\begin{abstract}
Introduction. To compare the diagnostic values of laboratory variables, to present evaluations of the diagnostic test for asymmetric dimethyl arginine (ADMA), rheumatoid factor (RF), C-reactive protein (CRP), and $\mathrm{DAS}_{28}$ index, and to define the effect of untreated rheumatoid arthritis on endothelial function. In order to determine whether ADMA changes depending on the disease evolution, ADMA was used as an indicator for endothelial dysfunction. Methods. Using an ELISA technology of DLD-DiagnostikaGMBH for the detection of ADMA, the samples of serum and urine have been examined in 70 participants (35 RA who were not treated, 35 healthy controls). RF was defined with the test for agglutination (Latex RF test) in the same participants. Results. Out of 35 examined patients with RA, RF appeared in 17 patients (sensitivity of the test, 51.42\%). In 20 of the 35 examined patients with RA, we found the presence of ADMA (sensitivity of the test, 57.14\%). Anti-CCP antibody was present in 24 examined patients with RA (sensitivity of the test, $68.57 \%$ ). Conclusion. ADMA has equal or very similar sensitivity and specificity to RF in untreated RA (sensitivity of $57.14 \%$ versus $48.57 \%$, specificity of $88.57 \%$ versus $91.42 \%$ ) in the detection of asymptomatic endothelial dysfunction in untreated RA.
\end{abstract}

\section{Introduction}

Rheumatoid arthritis (RA) is a disease which encompasses up to $1 \%$ of the whole population and is associated with an increased risk for onset and development of cardiovascular diseases (CVD). Data show that those patients have 30-60\% increased risk for CVD in comparison with patients with osteoarthritis [1]. Patients with RA with disease duration of more than 10 years have increased risk of myocardial infarction [2] and more expressed process of atherogenesis because of the chronic systemic inflammation.
Circulatory markers of the systemic inflammation significantly increase the risk of cardiovascular morbidity and mortality in this group of patients, far more than traditional risk factors such as smoking, diabetes, and hypertension [39]. There are numerous analogues between RA and atheroclerosis, including macrophages, T-cell activation, unbalance between $\mathrm{T}$ helper 1 and $\mathrm{T}$ helper 2 lymphocytse, increased level of circulatory reactants of the acute phase and adhesion molecules, increased production of endothelins, oxidative radicals and increased neoangiogenesis in early but as well in long-lasting RA. Endothelial dysfunction occurs in the 
absence of manifest CVD and is not connected with traditional atherosclerotic risk factors [10-12].

1.1. Biomarkers for Assessment of Endothelial Dysfunction. Few classes of measurable serum proteins are used in the assessment of cardiovascular system:

(1) biomarkers of myocyte injury: troponin I, troponin $\mathrm{T}$, creatine kinase isoenzymes (CK-MB), and myoglobin;

(2) biomarkers of myocyte stress: natriuretic peptides-A type (ANP), B type (BNP), adrenomedullin, midregional proadrenomedullin, and ST2;

(3) biomarkers of remodeling: (MMPs) 1,2,7,8,9; (TIMPs) 1,2 ; procollagen type III;

(4) Biomarkers of endothelial dysfunction: P-Selectin, scCAM-1, semi-carbazide sensitive amine oxidase (SSAO), vascular adhesion protein 1 (VAP-1), ADMA and SDMA, von Willebrandt factor, L-arginine, and nitric oxide metabolites $\left(\mathrm{NO}_{x}\right)$;

(5) biomarkers of inflammation: CRP, IL-1, IL-6, IL-10, TNF- $\alpha$;

(6) neurohormonal biomarkers: endothelin 1 (ET-1), bigendothelin 1 (Big ET-1).

Of the whole markers of the endothelial dysfunction, dimethyl derivatives of the amino acid L-Arginine incite greatest attention. There are two stereoisomer shapes of L-arginine, symmetric and asymmetric derivatives.

1.2. Symmetric Dimethyl Arginine (SDMA). This is a methylated derivative of amino acid Arginine. It is eliminated from the body exclusively with renal excretion. Therefore, SDMA plasma concentration is tightly connected with the renal function. Determination of the plasma level of SDMA is important for assessment of renal failure [13-15].

1.3. Asymmetric Dimethyl Arginine (ADMA). Synonyms (2S2-amino 5-[(aminodimethylaminomethylen) amino]) pentanoic acid; N, N-Dimethylarginine; at $\mathrm{C}_{8} \mathrm{H}_{18} \mathrm{~N}_{4} \mathrm{O}_{2}$ and natural chemical matter are normally present in plasma. They are metabolic products of continual processes of protein modification in cytoplasm in all human cells, tightly connected with essential amino acid L-arginine. ADMA interferes with $\mathrm{L}$-arginine in the production of nitric monoxide (NO) which has key role in the normal endothelial function. $\mathrm{NO}$ is synthesised in endothelial cells with the enzyme endothelial nitric oxide synthetase (NOS) (EC 1.14.13.39). It has 3 isoenzyme forms: endothelial (eNOS), neural (nNOS), and in macrophages and in other immune cells (iNOS) involved in immune response. NO is activated through haemoglobin.

Physiologic substrate, that is, precursor for NOS in this enzymatic process is $\mathrm{L}$-arginine which is converted into $\mathrm{NO}$ and L-citrulline. NOS is inhibited by the endogenous arginine metabolite ADMA. Plasma level of ADMA is increased in RA.

ADMA is synthesised with protein methylation, that is, with posttranslational modification of arginine residues, in different proteins, mostly in cell nucleus. Methylation of the arginine residues is catalyzed by the group of enzymes called protein arginine $\mathrm{N}$-methyl transferases (PRMTs). Basically, when proteins are proteolysed, free-methyl arginines are liberated.

The reaction is catalysed by the enzymes S-adenosylmethionine (SAM) as well as (protein methylases type I and II) (PRMTs). They transfer one or more methyl groups from donor S-adenosyl-methionine to L-arginine with proteins or polypeptides. Both subtypes PRMTs have ability to methylate monomethyl arginine (MMA), so that type 1 asymmetrically dimethylates arginine and creates ADMA, while type 2 catalyses symmetric dimethylation of arginine and creates SDMA. ADMA and MMA have the ability to inhibit NOS but not SDMA. After synthesis, ADMA migrates to extracellular space and plasma. Human being generates about $300 \mu \mathrm{mol} /$ daily (about $60 \mathrm{mg} /$ daily) of ADMA. Of this quantity, about $50 \mu \mathrm{mol} /$ daily is excreted in the urine. The elimination of ADMA is through urinary excretion after previous metabolization of the enzyme dimethylarginine dimethylaminohydrolase, dymethylargininasa, DDAH. There are 2 isoforms of $\mathrm{DDAH}_{1}$ and $\mathrm{DDAH}_{2}$ and which differ in the cell distribution. $\mathrm{DDAH}_{1}$ predominates in tissues that contain neural NOS, while $\mathrm{DDAH}_{2}$ is predominant in tissues with expression of endothelial NOS [16]. The main aim of this enzyme is degradation of methyl arginines, especially ADMA and MMA. The degradation of $80 \%$ of the daily production of ADMA is catalysed by DDAH [17].

\section{Defining the Problem}

RA is characterised with inflammation, key component in the onset and development of atherosclerosis. The inflammation, through activation of endothelial cells and through increase of the expression of leukocyte adhesion molecules, promotes proatherosclerotic environment. The endothelial dysfunction is an early preclinical marker for the onset of atherosclerosis and is often present in RA.

The endothelial dysfunction is closely connected with the inflammation, and therapeutic reduction of the inflammation leads towards its improvement. The assessment of the endothelial function is a useful tool in the identification and monitoring of the cardiovascular risk in patients with RA. Due to the fact that increased cardiovascular mortality is associated with RA, except the control of the activity of the disease, it is necessary to take measures, activities, and actions in the early detection and prevention of the cardiovascular risk.

The systemic inflammation presented in RA is characterised with the activation of the vascular endothelium, leukocytes, and platelets. Incapability, that is, vasodilatation dysfunction of the arterioles known as endothelial dysfunction, is the first phase for the appearance of the atherosclerotic damage. The endothelial dysfunction is localised on the level of arterioles, $<100 \mu \mathrm{m}$ in diameter, where the effect of NO is manifested, but it is forecondition for the appearance of atherosclerosis as ubiquitous disease of the middle-sized muscle arteries such as coronary, carotide, basilar, vertebral, 
and also with big calibre: aorta, iliacal, and arteries of the lower extremities.

The endothelial dysfunction is connected with several possible processes.

(1) Changes in the formation of the extracellular matrix and synthesis of the components of the basal membrane.

(2) Changes in the cell synthesis and liberation of vasoactive matters.

(3) Changes in the processes of coagulation, platelet aggregation, and athession.

(4) Proliferative processes of the smooth muscle cells and fibroblasts.

(5) Dysbalance between endothelial relaxing and contracting substances.

2.1. Suggested Mechanisms for the Increased Plasma Level of ADMA in RA. (1) Decreased activity of DDAH, a key enzyme which regulates ADMA degradation but not SDMA, is able to increase the ADMA plasma level. ADMA is liberated during degradation of proteins that contain methylated arginine residues [18]. NOS is inhibited by ADMA.

(2) Activity of DDAH is reversibly proportional with the presence of tumour necrotic factor alpha (TNF $\alpha)$ [1922], NOS, and S-nytrosylation. Because in RA quantities of TNF $\alpha$ oxygene radicals and 3-nitrotirosine are increased, it is hypothesised that the selective increase of ADMA plasma level in RA is the result of decreased DDAH activity in plasma. The chronical presence of proinflammatory cytokines as IL-1a, IL-1b, IL- 6 and TNF $\alpha$, and CRP from the synovial tissue directly influences the systemic endothelial dysfunction. Treatman with anti-TNF $\alpha$ in the 12th week significantly improves the endothelial vasodilatation of the brachial artery [23].

(3) Second possibility is that oxidative stress connected with RA can increase formation of ADMA through increased expression of protein arginine $1 \mathrm{~N}$-methyltransferase [24]. Substrates of these argine $1 \mathrm{~N}$ methyltransferases are proteins with side-chain arginine guanidine groups.

(4) Third possibility is that the inflammatory synovia in $\mathrm{RA}$ is with increased proliferation and potent apoptosis of the vascular endothelial cells [25]. The cultivated endothelial cells liberate more ADMA than SDMA [26]. Increased endothelial cell turnover in RA with successive liberation of ADMA during catabolism of the proteins results in increased level of ADMA in RA.

(5) Hypoxia in the inflamed synovia in RA decreases expression of DDAH [27]. Decreased DDAH activity increases the concentration of ADMA.

(6) The tendency towards insulin resistance is noticed in patients with RA, but positive association between plasma level of ADMA and insulin resistance is noticed in healthy individuals with different levels of insuline sensitivity [28]. This phenomenon is hypothetically connected with increased liberation of ADMA.

(7) The role of homocysteine as a risk factor for CVD is through the inhibitory effect of the regulatory production of
DDAH in the body. It is quickly regulated with vitamin B supplements. High endothelial LDL cholesterol increases the level of ADMA which in return inhibits the production of NO necessary for vasodilatation.

Increased level of ADMA is found in patients with homocysteinemia [29], coronary disease [30], peripheral arterial occlussive diseases [31], pulmonary hypertension [32], and as a result of smoking [33] and diabetes [34]. Common thing for all these conditions is that ADMA is endogenous inhibitor of NOS. New perspective and cross-sectional studies indicate that the increased level of ADMA is a risk factor for cardiovascular conditions and lethal outcome [35]. ADMA is significant as a new cardiovascular risk factor in RA.

ADMA activity is low in serum and is increased in the presence of endothelial dysfunction due to the presence of inflammation in RA. It is a very sensitive indicator of endothelial damage in comparison to the invasive and noninvasive functional measurements. The use of ADMA is a relatively simple, cheap, fast, and nonivasive method in detection of the early stadium of diesease and followup of the endothelial disorder. Therefore, its presence would be quantified with the level of inflammation in RA which correlates with the disease activity.

\section{Aims of the Study}

(1) To determine initial presence of ADMA in patients with RA.

(2) To examine the connection between plasma ADMA level and the activity of the disease with its characteristics. To investigate whether circulatory factors of NO metabolism, ADMA, reflect on clinical characteristics of RA.

(3) To determine whether mediators of the inflammatory reactions in RA influence microvascular, endothelial NO metabolism.

(4) To confirm the statement that the appearance of the subclinical atherosclerosis in RA is connected with the accumulation of the endogenous inhibitor of nitric monoxide synthetase and plasma level of ADMA.

(5) To determine correlations among plasma level of ADMA with the duration of disease, index of the strength of the disease (DAS-28), age of the patient and duration of disease, and evolution of disease before the beginning of treatment.

(6) To determine correlations between plasma level of ADMA and reactants of the acute phase.

(7) To determine whether seropositivity in RA influence plasma level of ADMA.

(8) To determine whether there is correlation between ADMA and anticyclic citrullinated peptide antibodies $\left(\right.$ anti- $\left.\mathrm{CCP}_{2}\right)$ from the second generation.

(9) On the base of the values of examined parameters that should be followedup and their correlation to determine whether biomarker would be the most 
adequate not only for early detection of endothelial damage but also for the best clinical, prognostic, and economic end-effect.

\section{Material and Methods}

In the patients examined for this study, the diagnosis of the disease was established on the basis of revised diagnostic criteria for the classification of rheumatoid arthritis, suggested in 1987 by the American Association for Rheumatism (ARA) [36]. In order for a patient to be diagnosed with rheumatoid arthritis, he or she must fulfill at least four out of seven criteria. Criteria from one to four are present for at least six weeks. The study involved 35 patients (female 27, male 8 ) suffering from RA and 35 healthy subjects (female 17, male 18) from the control group. Their average age was 55.57 years $( \pm 5.68)(39-65$ years) in the group with RA and 45.1 years $( \pm 11.37)$ (29-65 years) in the control group. The average duration of the disease in months from the beginning was $42.86( \pm 44.12)$ in the interval of $5-157$ months. None of the patients had been previously treated with oral corticosteroids. The rest of the patients refused to use other medicines before taking the examinations; Table 1.

4.1. Including Criteria. In this study, patients with RA, age 1865 , newly diagnosed and not treated would be included.

4.2. Excluding Criteria. From the study all patients/individuals with diseases or conditions that could directly or indirectly influence changes of results (diagnosed in the course of the study would be excluded), like the following:

(1) patients with past history for disease of the spleen, liver damage, renal, hematological, cardiological, neurological, and lung injuries, autoimmune diseases, AIDA, and age $<18$ years;

(2) patients suffering from conditions that affect lipid profile, such as smoking, diabetes, hypothyreosis, Cushing's syndrome, and obesity (body mass index $>30$, with family history of dyslipidemia);

(3) patients with acute infections, malignant diseases, febrile conditions;

(4) patients previously treated with some basic drug for RA, including CSs and NSAIDs;

(5) patients with hypertension, uric gastritis, urinary infections, systemic lupus erythematosus, mixed connective tissue disease, vasculitis, systemic scleroise, primary and secondary Raunaud phenomena, periferal vascular diseases, and congenital CVD;

(6) patients treated with antihypertensive, antidiabetic, and cardiologic therapy, drugs for decrease of the lipid profile, oral contraceptives, estrogens, progesteron, and tocopherol (vitamin E);

(7) patients previously blood transfused;

(8) patients in whom in 0-time would be found increased level of glycose, degradational products, like serum
TABle 1: Patients characteristics examined in the study.

\begin{tabular}{lcc}
\hline & $\begin{array}{c}\text { RA no. 35 } \\
\text { Value }(\mathrm{M} \pm \mathrm{SD})\end{array}$ & $\begin{array}{c}\text { Control healthy } \\
\text { group no. 35 } \\
\text { Value }(\mathrm{M} \pm \mathrm{SD})\end{array}$ \\
\hline Male/female relation & $8 / 27$ & $18 / 17$ \\
Middle average age (years) & $\begin{array}{c}55.57( \pm 5.68) \\
(39-65)\end{array}$ & $\begin{array}{c}45.10( \pm 11.37) \\
(29-65)\end{array}$ \\
$\begin{array}{l}\text { Middle duration (time) of } \\
\text { disease (month) }\end{array}$ & $\begin{array}{c}42.86( \pm 44.12) \\
(5-157)\end{array}$ & $\begin{array}{c}0.00( \pm 0.00) \\
(0.00-0.00)\end{array}$ \\
$\begin{array}{l}\text { Previous therapy with oral } \\
\text { corticosteroids } \\
\text { (no. of patients) }\end{array}$ & 0 & 0 \\
$\begin{array}{l}\text { Previus therapy with } \\
\text { methotrexate } \\
\text { (no. of patients) }\end{array}$ & & 0 \\
\hline
\end{tabular}

and urine creatinin, serum urea, hypertension, and changes in hematological parameters or enzymatic status.

All patients took part in this study voluntarily, so the ethical criterion was not breached during our work.

4.3. Clinical Evaluation of Disease Activity. Changes in the evolution of disease, that is, clinical improvements, would be assessed through suitable indexes of activity (clinical parameters) (Disease Activity Score-DAS 28 ) [37-40]. The index uses mathematical formula in order to get unique composite quantitative score composed of palpatory painfully sensitive joints (maximal score 28), swollen joints (maximal score 28), Westergren ESR, and patients global evaluation for disease activity (0-100 mm Visual Analogue Scale-VAS).

$\mathrm{DAS}_{28}$ index ranges from 0 to 10 , and score below 3.2 qualifies the disease as low active.

$\mathrm{DAS}_{28}: 0.560 .56 \sqrt{ } 0-28$ palpatory painfully sensitive joints $+0.28 \sqrt{ } 0-28$, swallen joints $+0.70\left(\log _{n}\right.$ ESR $)+0.014$ (global estimation of the patient for disease activity: VAS $0-$ 100).

4.4. Biochemical Laboratory Examination. For a clinical assessment of the basic disease, the following laboratory variables needed to be measured: haemogram and differential haemoalysis, reactors of acute phase, anti-CCP 2 antibody, C-reactive protein (CRP), rheumatic factor (RF), alkaline phosphatase (AP), aspartate aminotransferase (AST), alanine aminotransferase (ALT), creatinine kinase (CK), lactate dehydrogenase $(\mathrm{LDH})$, urea and creatinine in serum, and Asymmetric dimetil L-arginine (ADMA).

4.5. Determination of the Activity of Asymetric Dimethyl LArginin (ADMA): ELISA Method (DLD Diagnostics, GMBH) Enzyme Immunoassay. For quantitative determination of the endogenous Asymetric dimethyl L-arginine (ADMA) in serum or plasma.

Principle: ADMA is adhered in solid phase on microtiter plate. ADMA standard, samples, and positive control are preacylated, in combination with rabbit anti-N-acyl-ADMA, 
TABLE 2: Distribution of ADMA, reactant of acute phase and other laboratory variables in patients with RA and healthy control group.

\begin{tabular}{|c|c|c|c|c|}
\hline & $\begin{array}{c}\text { Ra not treated group } \\
\text { no. } 35 \\
\text { Value }(\mathrm{M} \pm \mathrm{SD})\end{array}$ & $\begin{array}{c}\text { RA }^{\text {sero- }} \\
\text { no. } 18 \\
\text { Value }(\mathrm{M} \pm \mathrm{SD})\end{array}$ & $\begin{array}{c}\text { RA }^{\text {sero+ }} \\
\text { no. } 17 \\
\text { Value }(\mathrm{M} \pm \mathrm{SD})\end{array}$ & $\begin{array}{c}\text { Control healthy group } \\
\text { no. } 35 \\
\text { Value }(\mathrm{M} \pm \mathrm{SD})\end{array}$ \\
\hline & Positive/negative & Positive/negative & Positive/negative & Positive/negative \\
\hline $\begin{array}{l}\text { ADMA } \\
+>0.75 \mu \mathrm{mol} / \mathrm{L}\end{array}$ & $\begin{array}{c}20 / 15 \\
08.10( \pm 0.75) \\
(0-210) \\
\end{array}$ & $\begin{array}{c}7 / 11 \\
11.22( \pm 0.72) \\
(0-110) \\
\end{array}$ & $\begin{array}{c}13 / 4 \\
13.16( \pm 0.40) \\
(0-210) \\
\end{array}$ & $\begin{array}{c}4 / 31 \\
11.75( \pm 0.22) \\
(55.20-105.33) \\
\end{array}$ \\
\hline $\begin{array}{l}\text { Sedimentation } \\
+\geq 16\end{array}$ & $\begin{array}{c}25 / 10 \\
46.43( \pm 41.79) \\
(1.0-110)\end{array}$ & $\begin{array}{c}11 / 7 \\
40.70( \pm 37.63) \\
(1.0-110)\end{array}$ & $\begin{array}{c}13 / 4 \\
51.38( \pm 37.37) \\
(1.0-110)\end{array}$ & $\begin{array}{c}3 / 32 \\
7.31( \pm 7.10) \\
(1.0-31)\end{array}$ \\
\hline Anti $\mathrm{CCP}_{2} \geq 1.26$ & $\begin{array}{c}24 / 11 \\
1.82( \pm 0.71) \\
(0.91-2.0) \\
\end{array}$ & $\begin{array}{c}12 / 6 \\
1.45( \pm 0.48) \\
(0.91-1.5) \\
\end{array}$ & $\begin{array}{c}11 / 6 \\
1.76( \pm 0.80) \\
(0.91-1.9) \\
\end{array}$ & $\begin{array}{c}1 / 34 \\
0.84( \pm 0.09) \\
(0.90-1.27) \\
\end{array}$ \\
\hline $\begin{array}{l}\mathrm{RF} \\
+\geq 8 \mathrm{IU} / \mathrm{mL}\end{array}$ & $\begin{array}{c}18 / 17 \\
335.09( \pm 515.11) \\
(0.00-512)\end{array}$ & $\begin{array}{c}0 / 18 \\
0.00( \pm 0.00) \\
(0.00-0.00)\end{array}$ & $\begin{array}{c}17 / 0 \\
601.67( \pm 622.68) \\
(32-1024)\end{array}$ & $\begin{array}{c}3 / 32 \\
11.69( \pm 40.69) \\
(0.00-128)\end{array}$ \\
\hline $\mathrm{DAS}_{28}+\geq 3.2$ & $\begin{array}{c}29 / 6 \\
5.81( \pm 1.44) \\
(1.76-6.01)\end{array}$ & $\begin{array}{c}14 / 4 \\
5.30( \pm 1.55) \\
(1.72-6.01)\end{array}$ & $\begin{array}{c}16 / 1 \\
4.01( \pm 1.29) \\
(1.39-5.81)\end{array}$ & $\begin{array}{c}0 / 35 \\
0.00( \pm 0.00) \\
(0.00-0.00)\end{array}$ \\
\hline
\end{tabular}

incubated for $15-20 \mathrm{~h}$ at $2-8^{\circ} \mathrm{C}$. After that they are washed, and second antibody is added, anti-rabbit IgG, conjugated with peroxidase. After $1^{-}$hour incubation a room temperature they are washed. In order to achieve colour, tetramethylbenzidine is added as a substrate solution (TMV). After 20-30 minutes incubation, it is stopped with adding sulphur acid. The absorbtion is read on $450 \mathrm{~nm}$ on automatical microtitar reader. With the standard figureis determined ADMA concentration. Basically, the quantity of antibodies adhered in the solid phase of ADMA is reversely proportional to the concentration of ADMA in the samples.

Refererent values: ADMA in serum 0.4-0.75 micromol/L.

Determination of the C-reactive protein (CRP) and rheumatoid factor (RF) with test for agglutination (Latex CRP test). (BioSystems S. A. Reagens \& Instruments Costa Brava 30, Barcelona, Spain).

Refererent values are $+>6 \mathrm{mg} / \mathrm{L} \mathrm{CRP}$ in serum; $+>8 \mathrm{mg} / \mathrm{L}$ for RF in serum.

Determination of anticyclic cetrullinated peptide antibodies (anti-CCP ${ }_{2}$ ) with semiquantitative/qualitative ELISA technique, based on the detection of IgG autoantibodies in human serum or plasma, directed towards synthetic cyclic citrulated peptides (CCPs) that contain modified arginine residues. The DIA-STAT anti-CCP (Axis-Shield Diagnostics).

Refererent values are $+>1.26$ positive values for anti-CCP in serum.

Determination of the erythrocyte sedimentation rate (ESR) with quantitative method of Westergren with normal values for males is $7-8 \mathrm{~mm}$, for woman $11-16 \mathrm{~mm}$.

\section{Statistical Analysis}

Predictive values for positive and negative results and accuracy of examined marks were defined with the test of sensitivity and specificity. Analysis of the structure of numeric series is made by the measures of the central tendency (average) and measures of dispersion (standard deviation); analysis of the structure of the attributive statistical series is made by coefficients of correlations and proportions; analysis of correlation between numeric statistical series is made by Pearson's coefficient of correlation- $p$; analysis of correlation between attributive statistical series is made by Pearson's $\chi^{2}$-test. To test the significance of differences between two arithmetical medians that is, proportions Student's $t$-test is used and a Wilcoxon-matched test for independentexamples. To test the significance of differences among three or more arithmetical medians, analysis of variance (ANOVA) is used. A $P$ value between 0.05 and 0.1 was taken as statistically significant. The results would be statistically processed with the following statistical methods and shown with statistical package Statististica 7.0.

\section{Results}

Of all the examined patients with RA, ADMA is detected in 20 patients $(57,14 \%)$, about acute phase reactant, $\mathrm{RF}$ was detected in 17 patients (48.57\%), anti-CCP antibody in 23 patients $(65.71 \%)$, CRP in 14 patients $(40 \%)$, and sedimentation in 27 patients (77.14\%). In the healthy control group, $\mathrm{RF}$ was present in 2 patients (5.71\%). $\mathrm{DAS}_{28}$ is present in 28 patients with RA (80\%). Among 18 RF negative patients, 7 patients (38.88\%) were ADMA positive. Among $17 \mathrm{RF}$ positive RA patients, presence of ADMA was found in 13 (76.47\%) patients. In the healthy control group, 4 patients (11.42\%) were ADMA positive; Table 2.

Diagnostic value of ADMA in patients with rheumatoid arthritis (RA) sensitivity, specificity, and predictive values of the positive and negative tests as well as their precision is shown in Table 3.

ADMA has equal.or very similar sensitivity and specificity from RF in untreated RA (sensitivity $57.14 \%$ versus 
TABLE 3: Diagnostic values of ADMA, and other labaratory variables in patients with RA.

\begin{tabular}{|c|c|c|c|c|c|}
\hline & $\begin{array}{c}\text { Sensitivity } \\
\%\end{array}$ & $\begin{array}{l}\text { Specificity } \\
\%\end{array}$ & $\begin{array}{c}\text { Predictive values for } \\
\text { the positive test } \\
\%\end{array}$ & $\begin{array}{c}\text { Predictive values for } \\
\text { the negative test } \\
\%\end{array}$ & $\begin{array}{c}\text { Accuracy } \\
\%\end{array}$ \\
\hline $\begin{array}{l}\text { ADMA } \\
\text { RA no. } 35\end{array}$ & 57.14 & 88.57 & 83.33 & 32.60 & 72.85 \\
\hline $\begin{array}{l}\text { ADMA } \\
\mathrm{RA}^{-} \text {no. } 18\end{array}$ & 38.88 & 88.57 & 63.63 & 26.19 & 71.69 \\
\hline $\begin{array}{l}\text { ADMA } \\
\text { RA }^{+} \text {no. } 17\end{array}$ & 76.47 & 88.57 & 76.47 & 11.42 & 84.61 \\
\hline $\begin{array}{l}\text { Sedimentation } \\
\text { RA no. } 35\end{array}$ & 71.42 & 91.42 & 89.28 & 23.80 & 81.42 \\
\hline $\begin{array}{l}\text { Sedimentation } \\
\mathrm{RA}^{-} \text {no. } 18\end{array}$ & 61.11 & 91.42 & 78.57 & 17.94 & 81.13 \\
\hline $\begin{array}{l}\text { Sedimentation } \\
\mathrm{RA}^{+} \text {no. } 17\end{array}$ & 76.47 & 91.42 & 81.25 & 11.11 & 86.53 \\
\hline $\begin{array}{l}\text { Anti CCP antibody } \\
\text { RA no. } 35\end{array}$ & 68.57 & 97.14 & 96 & 24.44 & 82.85 \\
\hline $\begin{array}{l}\text { Anti CCP antibody } \\
\mathrm{RA}^{-} \text {no. } 18\end{array}$ & 66.66 & 97.14 & 92.30 & 15 & 86.79 \\
\hline $\begin{array}{l}\text { Anti CCP antibody } \\
\mathrm{RA}^{+} \text {no. } 17\end{array}$ & 64.70 & 97.14 & 91.66 & 15 & 86.53 \\
\hline $\begin{array}{l}\text { RF } \\
\text { RA No35 }\end{array}$ & 51.42 & 91.42 & 85.70 & 34.69 & 71.42 \\
\hline $\begin{array}{l}\mathrm{RF} \\
\mathrm{RA}^{-} \text {no. } 18\end{array}$ & 0 & 91.42 & 0 & 36 & 60.37 \\
\hline $\begin{array}{l}\mathrm{RF} \\
\mathrm{RA}^{+} \text {no. } 17\end{array}$ & 100 & 91.42 & 85 & 0 & 94.23 \\
\hline $\begin{array}{l}\text { DAS }_{28} \\
\text { RA no. } 35\end{array}$ & 82.85 & 100 & 100 & 14.63 & 91.42 \\
\hline $\begin{array}{l}\mathrm{DAS}_{28} \\
\mathrm{RA}^{-} \text {no. } 18\end{array}$ & 77.77 & 100 & 100 & 10.25 & 92.45 \\
\hline $\begin{array}{l}\mathrm{DAS}_{28} \\
\mathrm{RA}^{+} \text {no. } 17\end{array}$ & 94.11 & 100 & 100 & 2.77 & 98.07 \\
\hline
\end{tabular}

$48.57 \%$, specificity $88.57 \%$ versus $94.28 \%$ ) in the detection of RA.

6.1. Association between Asymmetric Dimethylarginine and Disease Activity Score $\left(D A S_{28}\right)$ in Patients with Rheumatoid Arthritis. Among 35 patients with RA, DAS 28 was replaced in 29 patients $(82.85 \%)$. In 17 seropositive RF patients, replacement of $\mathrm{DAS}_{28}$ was detected in 16 patients $(94.11 \%)$. Of these $16 \mathrm{DAS}_{28}$ patients, 9 were ADMA positive (56.25\%). Among 18 seronegative RF patients, replacement of $\mathrm{DAS}_{28}$ was found in 14 patients $(77.77 \%)$. Of these $14 \mathrm{DAS}_{28}$ patients, 5 were ADMA positive (35.71\%), and their $\mathrm{M} \pm \mathrm{SD}$ was $6.03 \pm$ 0.21 .

Seropositive RF patients have bigger ADMA value of circumference than seronegative RF patients $(13,16( \pm 0,40)$ versus $11,22( \pm 0,72)$ and bigger $\mathrm{DAS}_{28}$ index of intensity of disease $(6.03 \pm 0.21)$ versus $(3.75 \pm 0.85)$. Between these two groups of ADMA), there is no statistical connection $(P=$ $0.74)$; see Table 2.

There was no statistical connection using the Wilcoxonmatched test between the $\mathrm{DAS}_{28}$ index in RF seropositive and seronegative patients $(P=0.48)$ and between two groups of $\mathrm{DAS}_{28}, \mathrm{ADMA}$ positive patients and seronegative patients $(P=0.33)$.

(1) Statistical relation was found using the Wilcoxonmatched test between ADMA in RA and age, duration of disease, RF, CRP, sedimentation, and morning rigid, in the same group for $P<0.05$ (ADMA vs age $P=0.000$; ADMA vs duration of disease, $P=0.000$; ADMA vs RF, $P=0,015$; ADMA vs CRP $P=0,030$; ADMAvsSedimentation, $P=0,000)$.

(2) There was no statistical connection using the Wilcoxon-matched test between ADMA in RA and healthy control group for $P<0.05(P=0.064)$, Figure 1.

\section{Discussion}

Not only the ever growing prevalence of the CVD in RA, but also the use of drugs that change the disease activity in disease treatment contributes to the deepening of the investigations towards finding easy, cheap, and practical 


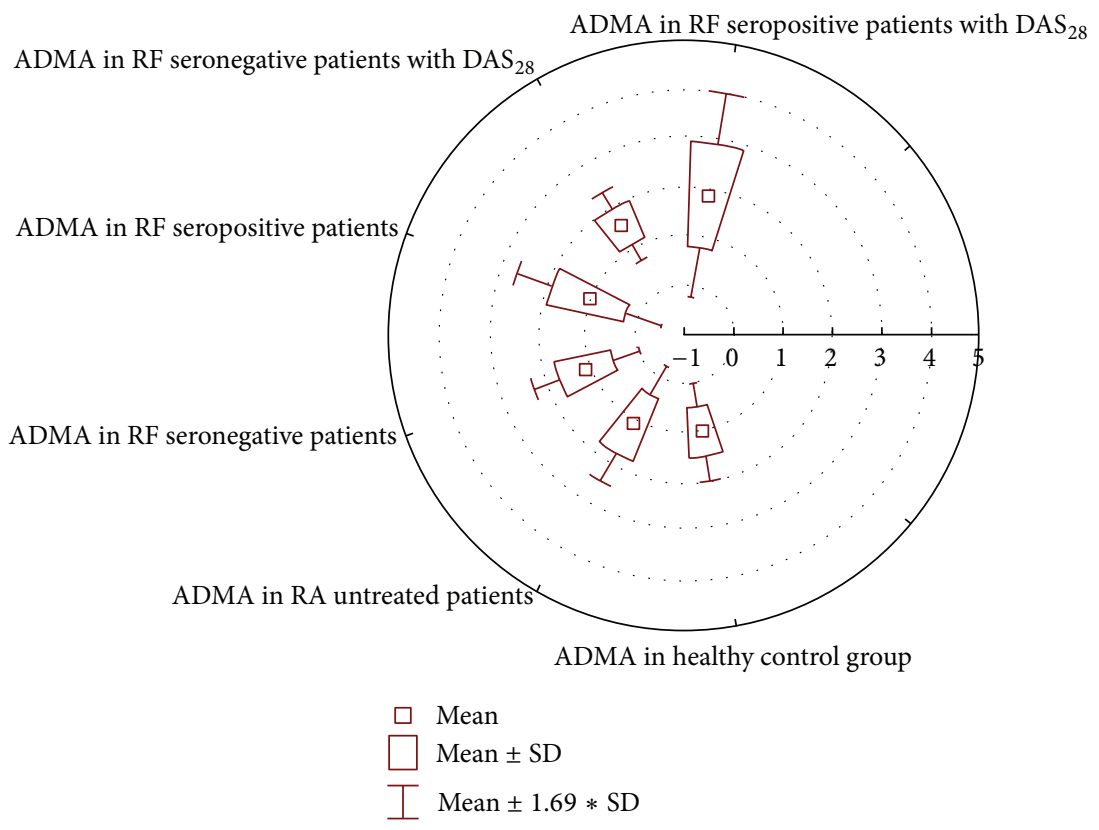

FIGURE 1: Distribution of asymmetric dimethylarginine (ADMA) in serum (0.4-0.75 micromol/L).

screening method, in order to detect the early stadium of disease of the endothelium.

There are several biomarkers as indicators for endothelial dysfunction such as endothelial vasoactive substances, leukocyte athesion substances, proinflammatory cytokines, prostaglandins, reactants of the acute phase, hormones, enzymes. Everyone has its own importance in the functioning of the blood vessels. ADMA is the unique substance on which the multifunctional role of $\mathrm{NO}$ depends, but as endogenous antiatherogenic molecule. Direct effect on the autoregulation of the normal myogenic activity and vasomotion (potent vasodilator effect), athession (inhibition of the platelet aggregation, inhibition of athession of the monocytes and leukocytes in normal vascular endothelium), proliferation (inhibition of proliferation of vascular smooth muscle cells), with basic aim achievement and maintenance of trans musculare, capillary pressure. ADMA has indirect effect on the process of atherosclerosis: it decreases vascular liberation of superoxide radicals involved in the inflammatory and cytokine processes and inhibition of LDL oxydation.

Until recently ADMA was detected with liquid chromatography, making it complex, inaccessible, technologically dependent, and expensive. With the introduction of ELISA method in the detection of ADMA, determination becomes more accessible and more practical.

ADMA plasma level is increased in RA without CVD or presence of risk factors. There is strong association between ADMA and anticyclic citrulated peptide antibodies (anti$\mathrm{CCP}_{2}$ ) from the second generation in early RA without cardiovascular risk factors as a result of the activity of disease and inflammatory activation. Our case shows that there is association between ADMA and anticitrulated peptide antibodies (anti-CCP 2 ) in early RA [41-44]. ADMA plasma level shows dependence on duration and disease evolution.
Seropositivity in RA has influence on ADMA plasma level. It shows in our example that patients with presence of RF with $\mathrm{DAS}_{28}$ index of disease have higher ADMA induction than seronegative patients with $\mathrm{DAS}_{28}$. Statistical connection between disease duration and presence of ADMA show that untreated RA works an endothelium as one of visceral appearance of the disease.

Endothelial dysfunction has been suggested as an early event in the atherogenic process and as a novel predictor of CHD events; more recent longitudinal studies in the CHD arena provide some support for this proposition [45]. Several studies employing various "direct" measures of vascular function such as pulse wave analysis [46], flow-mediated vasodilation [47], and venous occlusion plethysmography [48] confirm endothelial dysfunction in RA patients. Where examined, such dysfunction has been linked to systemic inflammatory markers. Vaudo and associates [49] have provided more recent evidence for endothelial dysfunction in young to middle-aged patients with low disease activity (disease activity score), DAS $\leq 3.2$, and noted a strong association to average CRP levels. This finding agrees with the earlier observation of an early excess risk of vascular events in RA patients. Elevated LDL cholesterol also was an independent correlate to impaired vascular function in RA patients in the latter study. Other more recent studies also show impaired vessel stiffness with the technique of pulse wave velocity [50], and we have shown impaired forearm microvascular function using laser Doppler imaging in patients with RA in parallel with a greater systemic inflammatory response [51].

More recent longitudinal studies report improved endothelial function after antitumor necrosis factor (TNF)- $\alpha$ therapy $[52,53]$, but this benefit seems to be transient and linked to the pattern of change in systemic inflammatory 
markers on TNF blockade. Treatment with disease-modifying antirheumatic drugs (DMARDs) also improves endothelial function in patients with RA [48], so the mechanism employed to achieve inflammatory control may not be crucial to the improvement in endothelial function.

\section{Conclusion}

ADMA has high sensitivity in the detection of asymptomatic endothelial dysfunction in untreated RA. The practical significance of the determination of ADMA plasma level in everyday clinical practice results form the fact that the doctor, according to the results of its concentration could change not only diagnostic but also therapeutic tactics. With the followup of the dynamics of changes of concentration of ADMA, and they could judge for the nature and development of the disease and its outcome. These possibilities make determination of ADMA plasma level practically important for on-time information to the doctor, considering disease nature and its severity.

\section{Disclosure}

Trial registration number is A210895/12.

\section{References}

[1] D. J. Watson, T. Rhodes, and H. A. Guess, "All-cause mortality and vascular events among patients with rheumatoid arthritis, osteoarthritis, or no arthritis in the UK General Practice Research Database," The Journal of Rheumatology, vol. 30, no. 6, pp. 1196-1202, 2003.

[2] D. H. Solomon, E. W. Karlson, E. B. Rimm et al., "Cardiovascular morbidity and mortality in women diagnosed with rheumatoid arthritis," Circulation, vol. 107, no. 9, pp. 1303-1307, 2003.

[3] I. Del Rincón, D. H. O’Leary, G. L. Freeman, and A. Escalante, "Acceleration of atherosclerosis during the course of rheumatoid arthritis," Atherosclerosis, vol. 195, no. 2, pp. 354-360, 2007.

[4] R. Ross, "Atherosclerosis-an inflammatory disease," The New England Journal of Medicine, vol. 340, no. 2, pp. 115-126, 1999.

[5] H. Maradit-Kremers, P. J. Nicola, C. S. Crowson, K. V. Ballman, and S. E. Gabriel, "Cardiovascular death in rheumatoid arthritis: a population-based study," Arthritis \& Rheumatism, vol. 52, no. 3, pp. 722-732, 2005.

[6] I. Del Rincon, K. Williams, M. P. Stern, G. L. Freeman, and A. Escalante, "High incidence of cardiovascular events in a rheumatoid arthritis cohort not explained by traditional cardiac risk factors," Arthritis \& Rheumatism, vol. 44, pp. 2737-2745, 2001.

[7] I. Del Rincón, G. L. Freeman, R. W. Haas, D. H. O’Leary, and A. Escalante, "Relative contribution of cardiovascular risk factors and rheumatoid arthritis clinical manifestations to atherosclerosis," Arthritis \& Rheumatism, vol. 52, no. 11, pp. 3413-3423, 2005.

[8] S. Van Doornum, G. McColl, and I. P. Wicks, "Accelerated atherosclerosis: an extraarticular feature of rheumatoid arthritis?" Arthritis \& Rheumatism, vol. 46, no. 4, pp. 862-873, 2002.
[9] M. A. Gonzalez-Gay, C. Gonzalez-Juanatey, A. Piñeiro, C. Garcia-Porrua, A. Testa, and J. Llorca, "High-grade C-reactive protein elevation correlates with accelerated atherogenesis in patients with rheumatoid arthritis," The Journal of Rheumatology, vol. 32, no. 7, pp. 1219-1223, 2005.

[10] S. Hänsel, G. Lässig, F. Pistrosch, and J. Passauer, "Endothelial dysfunction in young patients with long-term rheumatoid arthritis and low disease activity," Atherosclerosis, vol. 170, no. 1, pp. 177-180, 2003.

[11] G. Vaudo, S. Marchesi, R. Gerli et al., "Endothelial dysfunction in young patients with rheumatoid arthritis and low disease activity," Annals of the Rheumatic Diseases, vol. 63, no. 1, pp. 3135, 2004.

[12] P. H. Dessein, B. I. Joffe, and S. Singh, "Biomarkers of endothelial dysfunction, cardiovascular risk factors and atherosclerosis in rheumatoid arthritis," Arthritis Research \& Therapy, vol. 7, no. 3, pp. R634-R643, 2005.

[13] S. M. Bode-Böger, F. Scalera, J. T. Kielstein et al., "Symmetrical dimethylarginine: a new combined parameter for renal function and extent of coronary artery disease," Journal of the American Society of Nephrology, vol. 17, no. 4, pp. 1128-1134, 2006.

[14] J. T. Kielstein, S. R. Salpeter, S. M. Bode-Boeger, J. P. Cooke, and D. Fliser, "Symmetric dimethylarginine (SDMA) as endogenous marker of renal function-a meta-analysis," Nephrology Dialysis Transplantation, vol. 21, no. 9, pp. 2446-2451, 2006.

[15] P. Wanby, T. Teerlink, L. Brudin et al., "Asymmetric dimethylarginine (ADMA) as a risk marker for stroke and TIA in a Swedish population," Atherosclerosis, vol. 185, no. 2, pp. 271-277, 2006.

[16] J. Murray-Rust, J. Leiper, M. McAlister et al., "Structural insights into the hydrolysis of cellular nitric oxide synthase inhibitors by dimethylarginine dimethylaminohydrolase," Nature Structural Biology, vol. 8, pp. 679-683, 2001.

[17] C. T. L. Tran, J. M. Leiper, and P. Vallance, "The DDAH/ADMA/ NOS pathway," Atherosclerosis Supplements, vol. 4, no. 4, pp. 3340, 2003.

[18] P. Vallance and J. Leiper, "Cardiovascular biology of the asymmetric dimethylarginine:dimethylarginine dimethylaminohydrolase pathway," Arteriosclerosis, Thrombosis, and Vascular Biology, vol. 24, no. 6, pp. 1023-1030, 2004.

[19] A. Ito, P. S. Tsao, S. Adimoolam, M. Kimoto, T. Ogawa, and J. P. Cooke, "Novel mechanism for endothelial dysfunction: dysregulation of dimethylarginine dimethylaminohydrolase," Circulation, vol. 99, no. 24, pp. 3092-3095, 1999.

[20] J. Leiper, J. Murray-Rust, N. McDonald, and P. Vallance, "S-nitrosylation of dimethylarginine dimethylaminohydrolase regulates enzyme activity: further interactions between nitric oxide synthase and dimethylarginine dimethylaminohydrolase," Proceedings of the National Academy of Sciences of the United States of America, vol. 99, no. 21, pp. 13527-13532, 2002.

[21] P. H. J. Remans, M. van Oosterhout, T. J. M. Smeets et al., "Intracellular free radical production in synovial T lymphocytes from patients with rheumatoid arthritis," Arthritis \& Rheumatism, vol. 52, no. 7, pp. 2003-2009, 2005.

[22] H. Kaur and B. Halliwell, "Evidence for nitric oxide-mediated oxidative damage in chronic inflammation. Nitrotyrosine in serum and synovial fluid from rheumatoid patients," FEBS Letters, vol. 350, no. 1, pp. 9-12, 1994.

[23] D. Hürlimann, A. Forster, G. Noll et al., "Anti-tumor necrosis factor- $\alpha$ treatment improves endothelial function in patients 
with rheumatoid arthritis," Circulation, vol. 106, no. 17, pp. 21842187, 2002.

[24] R. H. Böger, K. Sydow, J. Borlak et al., "LDL cholesterol upregulates synthesis of asymmetrical dimethylarginine in human endothelial cells: involvement of S-adenosylmethionine-dependent methyltransferases," Circulation Research, vol. 87, no. 2, pp. 99-105, 2000.

[25] J. Middleton, L. Americh, R. Gayon et al., "Endothelial cell phenotypes in the rheumatoid synovium: activated, angiogenic, apoptotic and leaky," Arthritis Research and Therapy, vol. 6, no. 2, pp. 60-72, 2004.

[26] R. H. Böger, S. M. Bode-Böger, P. S. Tsao, P. S. Lin, J. R. Chan, and J. P. Cooke, "An endogenous inhibitor of nitric oxide synthase regulates endothelial adhesiveness for monocytes," Journal of the American College of Cardiology, vol. 36, no. 7, pp. 2287-2295, 2000.

[27] L. J. Millatt, G. S. J. Whitley, D. Li et al., "Evidence for dysregulation of dimethylarginine dimethylaminohydrolase I in chronic hypoxia-induced pulmonary hypertension," Circulation, vol. 108, no. 12, pp. 1493-1498, 2003.

[28] E. B. Marliss, S. Chevalier, R. Gougeon et al., "Elevations of plasma methylarginines in obesity and ageing are related to insulin sensitivity and rates of protein turnover," Diabetologia, vol. 49, no. 2, pp. 351-359, 2006.

[29] T. Hedner, A. Himmelmann, and L. Hansson, "Homocysteine and ADMA-emerging risk factors for cardiovascular disease?" Blood Pressure, vol. 11, no. 4, pp. 197-200, 2002.

[30] V. P. Valkonen, J. Laakso, H. Päivä et al., "Asymmetrical dimethylarginine (ADMA) and risk of acute coronary events. Does statin treatment influence plasma ADMA levels?" Atherosclerosis Supplements, vol. 4, pp. 19-22, 2003.

[31] K. Sydow, B. Hornig, N. Arakawa et al., "Endothelial dysfunction in patients with peripheral arterial disease and chronic hyperhomocysteinemia: potential role of ADMA," Vascular Medicine, vol. 9, no. 2, pp. 93-101, 2004.

[32] M. Gorenflo, C. Zheng, E. Werle, W. Fiehn, and H. E. Ulmer, "Plasma levels of asymmetrical dimethyl-L-arginine in patients with congenital heart disease and pulmonary hypertension," Journal of Cardiovascular Pharmacology, vol. 37, no. 4, pp. 489492, 2001.

[33] W. Z. Zhang, K. Venardos, J. Chin-Dusting, and D. M. Kaye, "Adverse effects of cigarette smoke on no bioavailability: role of arginine metabolism and oxidative stress," Hypertension, vol. 48, no. 2, pp. 278-285, 2006.

[34] K. Y. Lin, A. Ito, T. Asagami et al., "Impaired nitric oxide synthase pathway in diabetes mellitus: role of asymmetric dimethylarginine and dimethylarginine dimethylaminohydrolase," Circulation, vol. 106, no. 8, pp. 987-992, 2002.

[35] F. Mittermayer, K. Krzyzanowska, and M. Wolzt, "Asymmetric dimethylarginine (ADMA): a cardiovascular risk factor," Wiener Klinische Wochenschrift, vol. 120, no. 15-16, pp. 462-466, 2008.

[36] F. C. Arnett, S. M. Edworthy, D. A. Bloch et al., "The American Rheumatism Association 1987 revised criteria for the classification of rheumatoid arthritis," Arthritis \& Rheumatism, vol. 31, no. 3, pp. 315-324, 1988.

[37] A. M. Van Gestel, M. L. L. Prevoo, M. A. van 'T Hof, M. H. van Rijswijk, L. B. A. van de Putte, and P. L. C. M. van Riel, "Development and validation of the European League Against Rheumatism response criteria for rheumatoid arthritis," Arthritis \& Rheumatism, vol. 39, no. 1, pp. 34-40, 1996.
[38] M. L. L. Prevoo, M. A. van 'T Hof, H. H. Kuper, M. A. van Leeuwen, L. B. A. van de Putte, and P. L. C. M. van Riel, "Modified disease activity scores that include twenty-eight-joint counts: development and validation in a prospective longitudinal study of patients with rheumatoid arthritis," Arthritis \& Rheumatism, vol. 38, no. 1, pp. 44-48, 1995.

[39] A. Balsa, L. Carmona, I. González-Álvaro, M. A. Belmonte, X. Tina, and R. Sanmartí, "Value of DAS-28 and DAS 28-3 as compared to ACR-defined remission in rheumatoid arthritis," The Journal of Rheumatology, vol. 31, pp. 40-46, 2004.

[40] M. L. L. Prevoo, A. M. van Gestel, M. A. van 'T Hof, M. H. van Rijswijk, L. B. A. van de Putte, and P. L. C. M. van Riel, "Remission in a prospective study of patients with rheumatoid arthritis. American rheumatism association preliminary remission criteria in relation to the disease activity score," British Journal of Rheumatology, vol. 35, no. 11, pp. 1101-1105, 1996.

[41] G. Vaudo, S. Marchesi, R. Gerli et al., "Endothelial dysfunction in young patients with rheumatoid arthritis and low disease activity," Annals of the Rheumatic Diseases, vol. 63, no. 1, pp. 3135, 2004

[42] A. Surdacki, J. Martens-Lobenhoffer, A. Wloch et al., "Plasma asymmetric dimethylarginine is related to anticitrullinated protein antibodies in rheumatoid arthritis of short duration," Metabolism, vol. 58, no. 3, pp. 316-318, 2009.

[43] M. Turiel, L. Tomasoni, S. Sitia et al., "Effects of long-term disease-modifying antirheumatic drugs on endothelial function in patients with early rheumatoid arthritis," Cardiovascular Therapeutics, vol. 28, no. 5, pp. e53-e64, 2010.

[44] F. Khan, B. Galarraga, and J. J. F. Belch, "The role of endothelial function and its assessment in rheumatoid arthritis," Nature Reviews Rheumatology, vol. 6, no. 5, pp. 253-261, 2010.

[45] M. E. Widlansky, N. Gokce, J. F. Keaney Jr., and J. A. Vita, "The clinical implications of endothelial dysfunction," Journal of the American College of Cardiology, vol. 42, no. 7, pp. 1149-1160, 2003.

[46] M. Wong, L. Toh, A. Wilson et al., "Reduced arterial elasticity in rheumatoid arthritis and the relationship to vascular disease risk factors and inflammation," Arthritis \& Rheumatism, vol. 48, no. 1, pp. 81-89, 2003.

[47] C. Gonzalez-Juanatey, A. Testa, A. Garcia-Castelo et al., "HLADRB1 status affects endothelial function in treated patients with rheumatoid arthritis," American Journal of Medicine, vol. 114, no. 8, pp. 647-652, 2003.

[48] R. Bergholm, M. Leirisalo-Repo, S. Vehkavaara, S. Mäkimattila, M. R. Taskinen, and H. Yki-Järvinen, "Impaired responsiveness to NO in newly diagnosed patients with rheumatoid arthritis," Arteriosclerosis, Thrombosis, and Vascular Biology, vol. 22, no. 10, pp. 1637-1641, 2002.

[49] G. Vaudo, S. Marchesi, R. Gerli et al., "Endothelial dysfunction in young patients with rheumatoid arthritis and low disease activity," Annals of the Rheumatic Diseases, vol. 63, no. 1, pp. 3135, 2004.

[50] K. M. Mäki-Petäjä, F. C. Hall, A. D. Booth et al., "Rheumatoid arthritis is associated with increased aortic pulse-wave velocity, which is reduced by anti-tumor necrosis factor- $\alpha$ therapy," Circulation, vol. 114, no. 11, pp. 1185-1192, 2006.

[51] D. Datta, W. R. Ferrell, R. D. Sturrock, S. T. Jadhav, and N. Sattar, "Inflammatory suppression rapidly attenuates microvascular dysfunction in rheumatoid arthritis," Atherosclerosis, vol. 192, no. 2, pp. 391-395, 2007. 
[52] C. Gonzalez-Juanatey, A. Testa, A. Garcia-Castelo, C. GarciaPorrua, J. Llorca, and M. A. Gonzalez-Gay, "Active but transient improvement of endothelial function in rheumatoid arthritis patients undergoing long-term treatment with anti-tumor necrosis factor $\alpha$ antibody," Arthritis Care and Research, vol. 51, no. 3, pp. 447-450, 2004.

[53] D. Hürlimann, A. Forster, G. Noll et al., "Anti-tumor necrosis factor- $\alpha$ treatment improves endothelial function in patients with rheumatoid arthritis," Circulation, vol. 106, no. 17, pp. 21842187, 2002. 


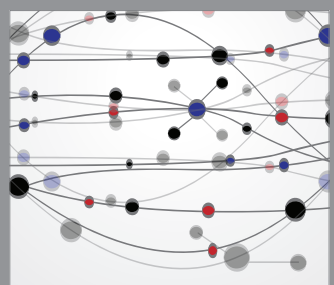

The Scientific World Journal
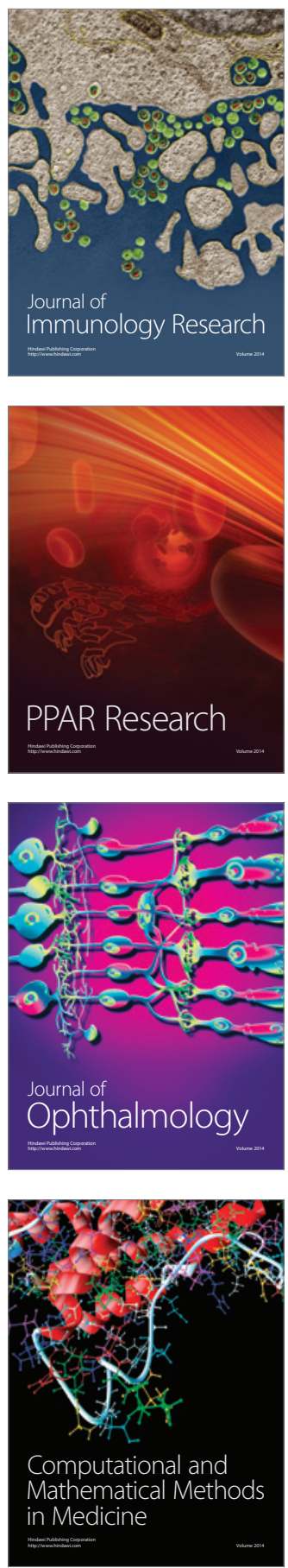

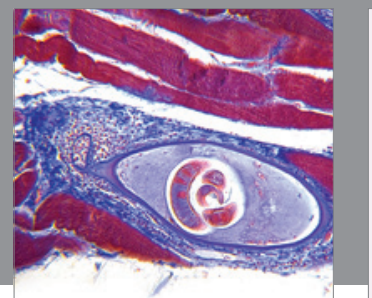

Gastroenterology

Research and Practice
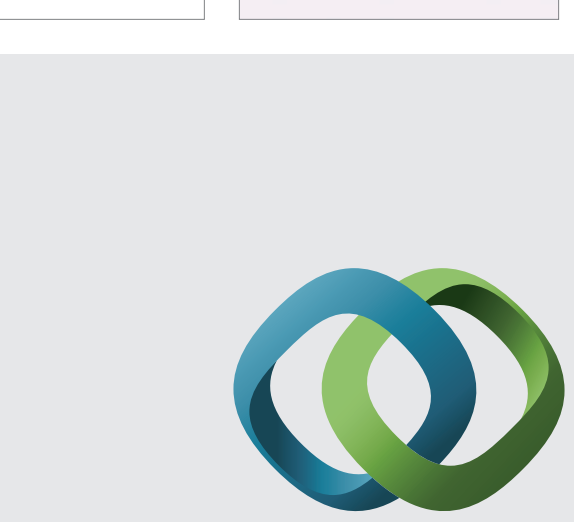

\section{Hindawi}

Submit your manuscripts at

http://www.hindawi.com
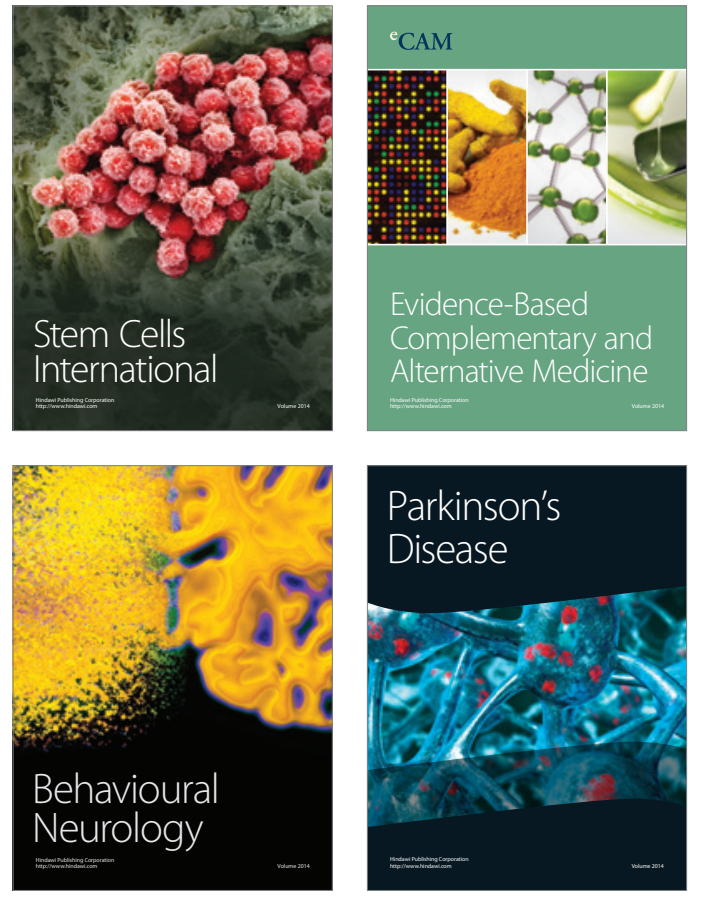
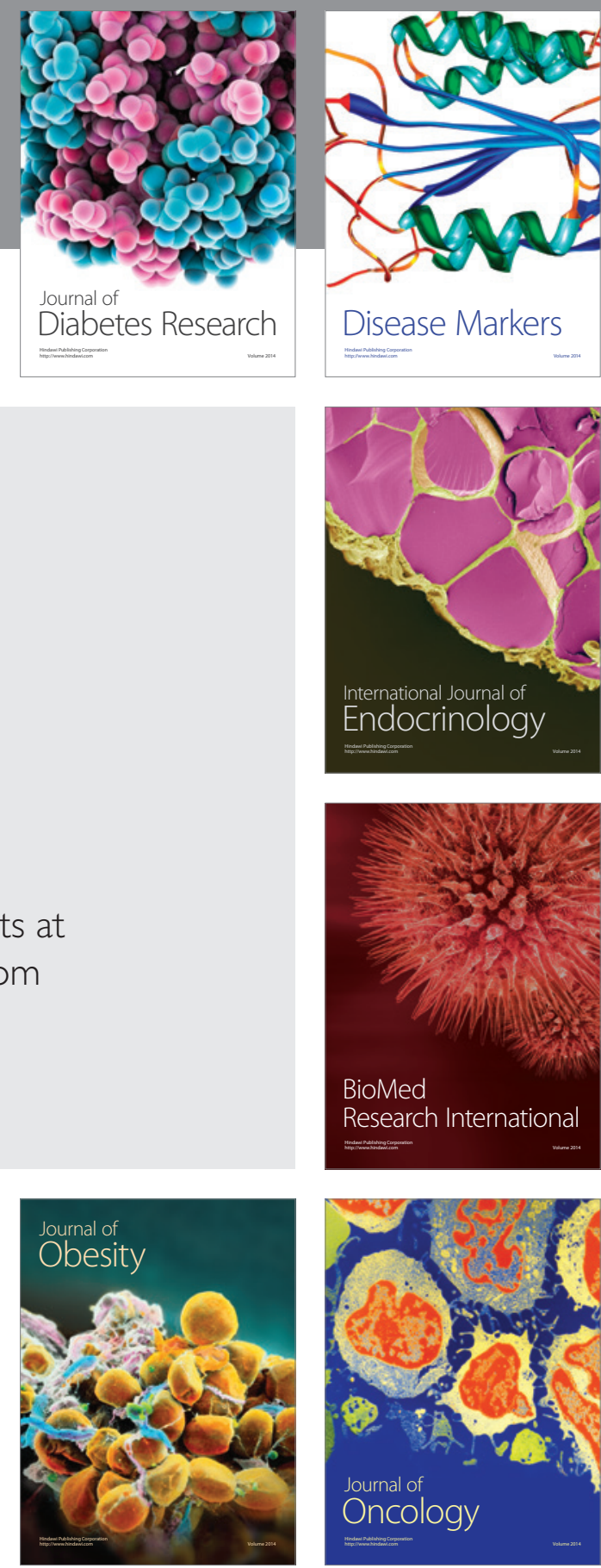

Disease Markers
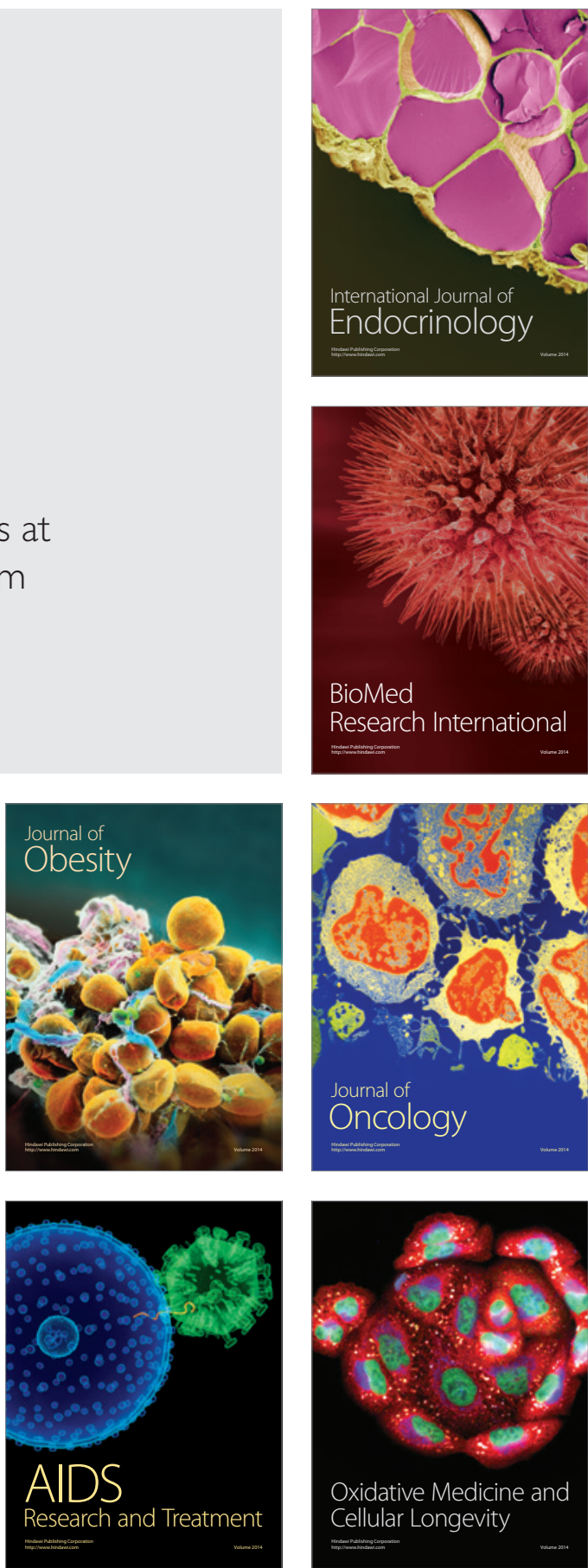